\title{
A Randomized, Controlled Trial of Ginseng Consumption on the Immune Response to a Moderate Exercise Stress Protocol in Non-Athletic Women
}

\author{
Patricia D. Biondo ${ }^{1}$, Linda J. McCargar ${ }^{1}$, Vicki J. Harber ${ }^{2}$ and Catherine J. Field*,1 \\ ${ }^{I}$ Alberta Institute for Human Nutrition, Department of Agricultural, Food and Nutritional Science, University of Alberta, \\ Edmonton, Alberta, T6G 2P5, Canada \\ ${ }^{2}$ Faculty of Physical Education \& Recreation, University of Alberta, Edmonton, Alberta, T6G 2H9, Canada
}

\begin{abstract}
Background: Ginseng is a popular herbal remedy that has been proposed to increase resistance to stress and enhance immune function. Regular moderate exercise results in an acute physiological stress that affects immune function.

Objective: This study was conducted to investigate the effects of daily consumption of a standardized ginsenosidecontaining North American ginseng (Panax quinquefolius) extract on immune function before, immediately after, and during recovery from moderate exercise in healthy, non-athletic women.

Research design and methods: A double-blinded randomized trial was conducted where healthy female subjects $(\mathrm{n}=12)$ were randomized to receive either ginseng $(1125 \mathrm{mg} / \mathrm{d} ; \mathrm{n}=6)$ or placebo $(\mathrm{n}=6)$ for four weeks. An exercise test was performed and peripheral blood collected before and after the four-week treatment period. Immune assays (phenotype analysis, neutrophil function, lymphocyte proliferation and natural killer cell cytotoxicity) were performed before, immediately after, and 30 minutes post-exercise.

Results: Ginseng-treated subjects had a lower $(\mathrm{P}<0.05)$ proportion of antigen mature CD4+CD45RO+ peripheral blood cells before and after exercise, and experienced a sustained reduction $(\mathrm{P}<0.05)$ in the proportions of total $\mathrm{CD} 28+$ and $\mathrm{CD} 4+\mathrm{CD} 28+$ cells during recovery from exercise. The ginseng group had significantly higher mitogen-stimulated neutrophil function (oxidative burst) at all exercise protocol time points $(\mathrm{P}<0.05)$. There were no effects of ginseng on the proportions of other immune cells, lymphocyte proliferation, or natural killer cell cytotoxicity in peripheral blood.
\end{abstract}

Conclusions: The consumption of ginseng for a four-week period improved the ability of neutrophils to respond to stimulation and produced changes consistent with less $\mathrm{T}$ cell activation after an acute exercise stress.

Keywords: Ginseng, ginsenosides, immune, exercise, randomized controlled trial, women.

\section{INTRODUCTION}

Ginseng is a popular herbal remedy that has been proposed to increase resistance to stress, enhance immune function, and improve physical performance [1,2]. Although the mechanisms underlying the claimed effects of ginseng remain to be elucidated, there is an extensive animal literature examining the effects of ginseng on the cardiovascular system, central nervous system, endocrine system, metabolism, and immune system [3].

The putative active compounds derived from ginseng root processing are the ginsenosides (saponin glycosides) and the water soluble poly- and oligosaccharides [4]. Both families of compounds are reported to modulate parameters of the immune system in vitro and in vivo. When incubated with human peripheral blood mononuclear cells ex vivo or mouse splenocytes in vitro, ginsenoside preparations from the Asian species Panax ginseng have been demonstrated to increase lymphocyte proliferation [5, 6], increase IL-2 and IL-4 cytokine production and decrease IFN- $\gamma$ secretion [6],

*Address correspondence to this author at the Department of Agricultural, Food and Nutritional Science, University of Alberta, 4-126A HRIF East, Edmonton, Alberta, T6G 2E1, Canada; Tel: (780) 492-2597; Fax: (780) 492-2011; E-mail: Catherine.Field @ualberta.ca and alter the expression of CD25, CD45RO and CD45RA with aging [5]. Among healthy human subjects, consumption of a Panax ginseng ginsenoside preparation (G115, containing $4 \% \mathrm{w} / \mathrm{w}$ ginsenosides) for 8-12 weeks increased phagocytic activity and chemotaxis of peripheral blood mononuclear cells [7], increased numbers of total lymphocytes and $\mathrm{T}$ helper cells [7], increased antibody titres, increased natural killer (NK) cell activity, and decreased the incidence of influenza or the common cold [8]. Recent randomized controlled trials have begun to report significant beneficial effects of the polysaccharide-rich North American ginseng extract COLD-fX ${ }^{\circledast}$ on the incidence and severity of acute respiratory illnesses and colds $[9,10]$. However, relatively few studies have focused on the potential immunomodulating effects of ginsenoside-containing extracts of North American ginseng (Panax quinquefolius) [11].

Regular moderate exercise results in an acute physiological stress that affects immune function [12,13]. Exercise in non-athlete populations has been reported to increase the concentrations of CD8+ and CD4+ T cells, NK cells, and IL2 receptor-positive cells in peripheral blood during or immediately after exercise [14-17], to increase resting concentrations of NK cells $[15,16]$, to increase the ability of lymphocytes [14] and neutrophils [18] to respond post-exercise, and to increase post-exercise neutrophil phagocytic function 
[18]. Little is known about the ability of ginseng consumption to modify the immune response to exercise. Recent animal studies indicate a potential stimulatory effect of 10 weeks of ginseng consumption on lymphocyte proliferation [19] and an inhibitory effect after one week of ginseng consumption on inflammatory cytokine (TNF- $\alpha$ and IL-1 $\beta$ ) production [20] in response to exercise stress. However, human trials have reported no effect of Panax ginseng consumption on measures of mucosal immunity (i.e. salivary secretory IgA levels) at rest or after exercise [21] or on peripheral blood lymphocyte concentrations (i.e. T cells, B cells, NK cells) measured at rest among endurance athletes [22]. In a randomized, controlled, crossover trial of North American ginseng consumption among healthy sedentary young men, we found that ginseng consumption for 35 days reduced peripheral blood CD8+ T cell concentrations and increased $e x$ vivo IL-2 production, but otherwise had a limited effect on the immune response to exercise [23]. The present study was conducted to investigate the effects of daily consumption of a standardized ginsenoside-containing North American ginseng (Panax quinquefolius) extract on immune function in a non-athletic population of women before, immediately after, and during recovery from an acute physiological stress (a moderate exercise protocol).

\section{MATERIALS AND METHODOLOGY}

\section{Subjects and Study Design}

Healthy female university students between the ages of 18 and 35, with a body mass index (BMI) of 20-27, a maximal oxygen consumption $\left(\mathrm{VO}_{2 \max }\right) \leq 40 \mathrm{ml} / \mathrm{kg} / \mathrm{min}$, and who were taking oral contraceptives, were recruited for the study. Individuals who smoked, were unable to exercise, had diabetes, thyroid, renal, or autoimmune disease, or who were taking any medications (other than oral contraceptives) or herbal supplements were excluded. Ethical approval for the study was obtained from the Human Ethics Review Committee of the Faculty of Agriculture, Forestry, and Home Economics, and all subjects gave informed consent prior to participation. Subjects were randomized to receive either ginseng or placebo for four weeks. Anthropometric variables (height, weight, body mass index, percent body fat) were assessed at baseline. Dietary intake, physical activity levels, and blood hemoglobin levels were assessed before and after the diet treatment period. An exercise stress protocol was also performed before and after the diet treatment period, during which blood was collected before, immediately after, and during recovery from the exercise stress protocol to measure select immune parameters (described below). All individuals involved in the exercise and immune measures were blinded to the participants' dietary treatment.

\section{Aerobic Fitness Assessment}

During the screening phase, $\mathrm{VO}_{2 \max }$ (a measure of aerobic fitness) was determined to establish each participant's ventilatory threshold (VT) for the exercise stress protocol [24]. The $\mathrm{VO}_{2 \max }$ test was conducted on a Monark $818 \mathrm{E}$ cycle ergometer (Varberg, Sweden). Respiratory gases were continuously monitored and averaged every 15 seconds on an automated metabolic measurement system (D-series Gas Exchange System, MedGraphics, CA, USA). Subjects started pedaling at a resistance of 1.0 kiloponds $(\mathrm{kp})$ and maintained the frequency of pedaling between 60 and 70 revolutions per minute. Every 2 minutes the resistance was increased by $0.5 \mathrm{kp}$, until VT was reached, after which resistance was increased by $0.5 \mathrm{kp}$ every minute until $\mathrm{VO}_{2 \max }$ was attained. VT was indicated by a decrease and plateau in $\mathrm{VE} / \mathrm{VCO}_{2}$ prior to a systematic increase with increased power output as well as a respiratory exchange ratio of greater than 1.05 [24]. Attainment of $\mathrm{VO}_{2 \max }$ was determined by (a) a leveling or decrease in $\mathrm{VO}_{2}$ with increasing workload $(0.5 \mathrm{kp} / \mathrm{min})$, (b) a plateau in heart rate and/or attainment of age-predicted maximum heart rate, (c) respiratory exchange ratio > 1.1, and (d) volitional fatigue [25].

\section{Ginseng Supplementation}

North American whole root ginseng extract powder $\left(\mathrm{CNT} 2000^{\circledR}\right)$ capsules and placebo capsules were provided by Chai-Na-Ta Corp. (Richmond, BC, Canada). CNT 2000® is a trademarked extract produced by a proprietary process, and is standardized to contain $8 \% \mathrm{w} / \mathrm{v}$ ginsenosides from North American ginseng [26]. The recommended dosage for North American ginseng is $0.5-3.0 \mathrm{~g}$ per day [27]. Participants received a total of $1125 \mathrm{mg}$ of the ginsenosideenriched extract daily, or a placebo (cornstarch), taken in the form of three capsules per day. Participants were instructed to take one capsule 30 minutes prior to eating breakfast, lunch, and supper for the duration of the study. Compliance was monitored orally through weekly telephone calls, and unused capsules were collected and counted at the end of the study period. Adverse events were recorded by participants and returned to the study coordinator at the end of the study period.

\section{Dietary Intake}

Before and after the diet treatment period, dietary intakes were assessed by three-day food records, completed by each participant for two weekdays and one weekend day. Food records were reviewed by study staff and confirmed for accuracy with each participant. Records were analyzed by Food Processor $\mathrm{II}^{\mathrm{TM}}$ for Windows (ESHA Research, Portland, OR, USA) to estimate intakes of total energy and macronutrients.

\section{Test Day Protocol}

The Modified Baecke Questionnaire on Physical Activity [28, 29] was completed prior to aerobic assessment. Height and weight were measured and body composition was determined by hydrodensitometry [30]. Residual lung volume was measured by helium dilution technique ([31]; SensorMedics 2450 Pulmonary Function Cart, Yorba Linda, CA, USA). Underwater weight was measured with a computerized strain-gauge system with percent body fat, fat mass, and fat-free mass estimated using the equation of Siri [32].

Resting energy expenditure (REE) was measured between 0700 and 0900 hrs. Participants were in a fasted state and had refrained from intense physical activity for 24 hours prior to the test. All participants were tested during the first seven days of a 21- or 28-day oral contraceptive pill preparation. Oxygen consumption was measured by indirect calorimetry (Vmax 29N metabolic cart, Sensormedics, Yorba Linda, CA, USA) using the Weir equation [33] to calculate energy expenditure (kcal/day). The exercise stress protocol and blood collection were performed at either 1400 or 1530 hrs to control for the diurnal variation in serum cortisol [34]. 
Participants were asked to refrain from physical activity on the day of testing and to cease eating at least two hours prior to the exercise protocol. Upon arrival in the lab, an intravenous catheter was inserted into the forearm prior to the start of the test and venous blood samples were collected serially before $(\mathrm{t}=-15 \mathrm{~min})$, immediately after $(\mathrm{t}=36 \mathrm{~min})$, and during recovery from $(t=66 \mathrm{~min})$ exercise. Participants performed 36 minutes of continuous exercise comprised of 6 minutes of warm-up at $1.5 \mathrm{kp}$ and $50 \mathrm{rpm}$, followed by 15 minutes at $80 \%$ VT, and then 15 minutes at $100 \%$ VT (60 to $70 \mathrm{rpm}$ ) on a stationary bicycle. VT was determined from the $\mathrm{VO}_{2 \max }$ test for each participant. Respiratory gases were collected to monitor substrate oxidation and respiratory exchange ratio. Analyzers were calibrated before, at the beginning of each 15 minute bout and after completion of the 36minute exercise bout with precision calibration gases.

\section{Immune Analyses}

A 10-mL sample of blood was collected at times $-15,36$ and $66 \mathrm{~min}$ (exercise beginning at $0 \mathrm{~min}$ ) to estimate the effect of ginseng and exercise on the type of immune cells present, neutrophil function, lymphocyte proliferation, and NK cell cytotoxic activity.

\section{Blood Mononuclear Cell Phenotypes}

Mononuclear lymphocyte phenotypes were identified by a direct immunofluorescence assay performed on an aliquot of whole blood, as previously described [35]. Commercial monoclonal antibodies labeled with fluorescein isothiocyanate, phycoerythrin, or biotin were used to identify $\mathrm{T}$ cells (CD3+), T helper cells (CD4+), T cytotoxic cells (CD8+), T cells expressing the CD28 costimulatory molecule (CD28+) or the IL-2 receptor (CD25+), monocytes (CD14+), NK cells and macrophages (CD16+), NK cells (CD16+CD56+), B cells $(\mathrm{CD} 20+)$ and antigen mature $(\mathrm{CD} 45 \mathrm{RO}+)$ and naïve $(\mathrm{CD} 45 \mathrm{RA}+) \mathrm{T}$ and $\mathrm{B}$ cells. All antibodies were purchased from Sigma-Aldrich Canada Ltd. (Oakville, ON), BD Bioscience (Mississauga, ON), or Serotec (Raleigh, NC). All biotin-labeled antibodies had an additional 30 minute incubation with strept-avidin-quantum red (Sigma-Aldrich) and then all cells were fixed with phosphate-buffered saline containing $1 \%(\mathrm{w} / \mathrm{v})$ paraformaldehyde (Anachemia Science, Montreal, QC) and analysed within 72 hours by flow cytometry (FACScan, Becton Dickinson, Sunnyvale, CA, USA) according to relative fluorescence intensity using CellQuest software (Becton Dickinson).

\section{Neutrophil Function}

Neutrophil oxidative burst activity was assessed in whole blood as previously described in detail [35]. In brief, the oxidation of dihydrorhodamine 123 (Molecular Probes, Eugene, OR, USA) to rhodamine 123 was measured before and at various time points $(5,10$ and $15 \mathrm{~min})$ after stimulation with phorbol myristate acetate (PMA, $3.2 \times 10^{3} \mathrm{nM}$; ICN). The oxidation of dihydrorhodamine was quantified by flow cytometry using the flow cytometer described above.

\section{Estimation of Lymphocyte Proliferation}

From the remaining blood, peripheral mononuclear cells and plasma were isolated on a Ficoll gradient of Histopaque1077 (Sigma-Aldrich Canada Ltd.) as previously described [36]. The isolated cells were resuspended in complete culture medium (RPMI 1640; Invitrogen, Burlington, ON, Canada) containing $4 \%(\mathrm{v} / \mathrm{v})$ fetal bovine serum, $2.5(\mathrm{v} / \mathrm{v}) \%$ HEPES, $0.1(\mathrm{v} / \mathrm{v}) \% 2.5 \mu \mathrm{mol}$ mercaptoethanol, and 1 (v/v) \% antibiotic/antimycotic (Invitrogen). Cells were seeded in triplicate in 96-well microtiter plates at 200,000 cells per well, and were cultured with or without phytohemagglutinin (PHA; 5 $\mathrm{ng} / \mathrm{L}$ ) or pokeweed mitogen (PWM; $55 \mu \mathrm{g} / \mathrm{mL}$ ) for 48 hours at $37{ }^{\circ} \mathrm{C}$ and $5 \% \mathrm{v} / \mathrm{v} \mathrm{CO}_{2}$. Eighteen hours prior to harvesting the cells, each well was pulsed with $0.5 \mu \mathrm{Ci}\left[{ }^{3} \mathrm{H}\right]$-thymidine (Amersham Biosciences, Baie D'Urfe, QC, Canada). The cells were harvested and disintegrations per minute (dpm) counted as previously described [35]. Stimulation indices were calculated as follows: $\left[{ }^{3} \mathrm{H}\right]$-thymidine (dpm) incorporated by stimulated cells / $\left[{ }^{3} \mathrm{H}\right]$-thymidine $(\mathrm{dpm})$ incorporated by unstimulated cells.

\section{NK Cell Cytotoxic Activity}

NK cytotoxicity was determined on peripheral blood mononuclear cells using a chromium release assay as previously described [37]. Briefly, NK-sensitive K562 human leukemic cells (target) (American Type Tissue Culture Collection, Manassas, VA) were incubated with sodium chromate $\left({ }^{51} \mathrm{Cr}\right.$; Amersham Pharmacia Biotech, Montreal, Quebec) and seeded in triplicate in 96-well, V-bottom microtitre plates. Lymphocytes were added at effector-to-target cell ratios varying from 3.125:1 to 50:1. Following a 4-hr incubation, aliquots of the supernatant were counted in a Gamma counter (Beckman Gamma 8000, Beckman Instruments) to determine the release of ${ }^{51} \mathrm{Cr}$. The percent specific lysis achieved by the effector cells for each sample was determined using the following formula: $\%$ specific lysis $=(\mathrm{ex}-$ perimental release - spontaneous release) / (maximum release - spontaneous release $) \times 100$. Spontaneous release was determined from the target cells incubated in the absence of effector cells. Maximum release was determined from detergent lysis of labeled target cells. The \% specific lysis for each effector to target ratio was plotted against the effector cell concentrations (NK cells; CD3-/16+/56+) of each ratio to calculate the lytic units. Lytic units were equivalent to the number of effector cells $\left(\times 10^{3}\right)$ required to lyse $30 \%$ of the target cells.

\section{Statistics}

All statistical analyses were conducted using the SAS statistical program (version 8.1, SAS Institute, Cary, NC). First, baseline data were analyzed to detect any differences between the experimental and control groups. Two-tailed, independent student's t-tests were conducted to compare subject demographics, anthropometric characteristics and physical activity indices. A mixed model repeated measures analysis [38] was used to detect differences between the two groups in the immune measures (i.e. immune cell phenotypes, lymphocyte proliferation, neutrophil oxidative burst, and natural killer cell cytotoxicity). The baseline and posttreatment data were then analyzed by a mixed model repeated measures analysis [38] to determine the effects of dietary treatment and exercise on the above immune measures, using baseline values as covariates for those immune measures that differed between groups prior to dietary treatment. For all repeated measures analyses, the appropriate covariance structure for each dataset was determined as per Wang and Goonewardene [38]. When a significant main 
Table 1. Subject Demographics and Characteristics at Baseline*

\begin{tabular}{|l|c|c|}
\hline & Placebo Group (n=6) & Ginseng Group (n=6) \\
\hline \hline Age $(\mathrm{yrs})$ & $24.5 \pm 1.4$ & $23.8 \pm 1.5$ \\
\hline Height $(\mathrm{cm})$ & $163 \pm 2$ & $62.3 \pm 3.6$ \\
\hline Weight $(\mathrm{kg})$ & $56.1 \pm 1.3$ & $23.1 \pm 1.0$ \\
\hline Body mass index $\left(\mathrm{kg} / \mathrm{m}^{2}\right)$ & $21.3 \pm 0.8$ & $20.9 \pm 0.9$ \\
\hline Percent body fat & $23.8 \pm 2.1$ & $1986 \pm 107$ \\
\hline Energy intake $(\mathrm{kcal} / \mathrm{day})$ & $1757 \pm 155$ & $71 \pm 4$ \\
\hline Protein intake $(\mathrm{g} / \mathrm{day})$ & $67 \pm 7$ & $302 \pm 20$ \\
\hline Carbohydrate intake $(\mathrm{g} / \mathrm{day})$ & $253 \pm 28$ & $58 \pm 5$ \\
\hline Fat intake $(\mathrm{g} /$ day) & $48 \pm 6$ & $1466 \pm 74$ \\
\hline REE $(\mathrm{kcal} / \mathrm{day})$ & $1383 \pm 34$ & $37.7 \pm 1.5$ \\
\hline VO ${ }_{\text {max }}(\mathrm{mL} / \mathrm{kg} / \mathrm{min})$ & $36.5 \pm 1.7$ & $7.2 \pm 0.5$ \\
\hline Physical activity index & $8.4 \pm 0.7$ & $134.8 \pm 3.5$ \\
\hline Blood hemoglobin $(\mathrm{g} / \mathrm{L})$ & $132.8 \pm 2.5$ & \\
\hline V & & \\
\hline
\end{tabular}

"Values are means \pm SEM. REE, resting energy expenditure; $\mathrm{VO}_{2 \max }$, maximal oxygen consumption. There were no significant differences between groups.

effect (diet or exercise) or interaction effect (diet $\times$ exercise) was found, differences between groups were identified by lsmeans. When there was no effect of dietary treatment, diet groups were combined to report the effect of exercise. For all measures, $\mathrm{P}<0.05$ was accepted as statistically significant. Results are presented as means \pm standard errors of means (SEM).

\section{RESULTS}

\section{Participant Characteristics}

Twelve healthy female university students $(24 \pm 1$ yrs $)$ started and completed the trial. Six women were randomized to the ginseng treatment and six were randomized to the placebo treatment. There were no significant differences between treatment groups in baseline demographics, anthropometric characteristics, energy and macronutrient intakes or physical activity or fitness measures (Table 1). All participants reported to be in good health prior to and throughout the study. Following the treatment period, energy $(1835 \pm 90$ $\mathrm{kcal} / \mathrm{d}, \mathrm{n}=12)$, protein $(64 \pm 3 \mathrm{~g} / \mathrm{d}, \mathrm{n}=12)$, carbohydrate $(253$ $\pm 22 \mathrm{~g} / \mathrm{d}, \mathrm{n}=12)$ and fat $(59 \pm 5 \mathrm{~g} / \mathrm{d}, \mathrm{n}=12)$ intakes were not significantly different between treatment groups, nor did they differ from baseline. Similarly, physical activity indices $(7.7 \pm 0.4, \mathrm{n}=12)$ and blood hemoglobin levels $(132 \pm 2 \mathrm{~g} / \mathrm{L}$, $\mathrm{n}=12$ ) did not differ between groups after the treatment period, or from baseline. However, this was a small trial and not sufficiently powered to determine if there was an effect of ginseng on these variables. There were a few adverse effects reported but these were minor and occurred in both groups. Among the six women randomized to ginseng treatment, one reported a headache and mild nausea on the first day of ginseng consumption, one reported stomach cramps and mild nausea during the first four days of ginseng consumption, and one subject reported a cold sore (herpes simplex labialis outbreak). Among the six women consuming the placebo, two reported occasional headaches.

\section{Immune Cell Phenotypes}

\section{Effect of Ginseng}

There were no differences between groups at baseline in any of the immune cell phenotypes measured. With the exception of CD4+ populations, the majority of blood lymphocyte phenotype proportions were not affected by ginseng treatment (Table 2). However, the proportion of antigen mature $(\mathrm{CD} 45 \mathrm{RO}+) \mathrm{CD} 4+$ cells was significantly lower among ginseng-treated subjects than placebo-treated subjects $(\mathrm{P}<0.001$; Fig. 1). In addition, there was a significant interaction effect between diet and exercise on the proportions of CD4+CD28+ and total CD28+ cells $(\mathrm{P}=0.01$ and $\mathrm{P}=0.03$, respectively). After four weeks of diet treatment, the proportions of both CD4+CD28+ and total CD28+ cells among the ginseng-treated subjects were reduced immediately postexercise and remained lower throughout the recovery period, whereas among the placebo-treated subjects, both cell phenotypes at recovery returned to levels not different from those seen pre-exercise (Fig. 2).

\section{Effect of Exercise}

Exercise significantly affected the relative proportions of most mononuclear cells populations measured (Table 2). The proportions of $\mathrm{CD} 3+, \mathrm{CD} 3+\mathrm{CD} 4+, \mathrm{CD} 4+\mathrm{CD} 45 \mathrm{RA}+$, and total $\mathrm{CD} 25+$ cells were all reduced immediately postexercise compared to pre-exercise values $(\mathrm{P}<0.05)$. Their proportions returned to pre-exercise levels at recovery, with the exception of total CD3+ and CD4+CD45RA+ cells, which remained lower $(\mathrm{P}<0.05)$. The proportions of CD16+CD56+ (NK cells) and total CD16+ cells were increased immediately post-exercise $(\mathrm{P}<0.05)$, but returned to pre-exercise levels at recovery. Total $\mathrm{CD} 45 \mathrm{RO}+$ and $\mathrm{CD} 8+\mathrm{CD} 45 \mathrm{RO}+$ proportions were higher at recovery than at pre-exercise, whereas total CD45RA+ and CD8+CD45RA+ proportions were lower at recovery compared to pre-exercise values $(\mathrm{P}<0.05)$. The proportions of $\mathrm{CD} 8+\mathrm{CD} 28+$ and 
Table 2. Effect of Exercise on Blood Lymphocyte Phenotypes*

\begin{tabular}{|c|c|c|c|c|}
\hline Lymphocyte Phenotype & Pre-Exercise $(t=-15$ min $)$ & Post-Exercise ( $t=36$ min $)$ & Recovery $(t=66 \mathrm{~min})$ & Exercise P-Value \\
\hline $\mathrm{CD} 3+\mathrm{CD} 4+$ & $43 \pm 1^{\mathrm{a}}$ & $36 \pm 1^{\mathrm{b}}$ & $41 \pm 2^{\mathrm{a}}$ & $\mathrm{P}<0.0001$ \\
\hline $\mathrm{CD} 3+\mathrm{CD} 8+$ & $21 \pm 1$ & $17 \pm 2$ & $17 \pm 2$ & NS \\
\hline $\mathrm{CD} 8+\mathrm{CD} 25+$ & $1.3 \pm 0.4$ & $0.7 \pm 0.1$ & $1.4 \pm 0.5$ & NS \\
\hline Total CD25+ & $13 \pm 1^{\mathrm{a}}$ & $11 \pm 1^{\mathrm{b}}$ & $13 \pm 1^{\mathrm{a}}$ & $\mathrm{P}<0.05$ \\
\hline $\mathrm{CD} 4+\mathrm{CD} 45 \mathrm{RA}+$ & $24 \pm 2^{\mathrm{a}}$ & $20 \pm 1^{\mathrm{b}}$ & $20 \pm 2^{\mathrm{b}}$ & $\mathrm{P}<0.0001$ \\
\hline $\mathrm{CD} 8+\mathrm{CD} 45 \mathrm{RO}+$ & $6 \pm 1^{\mathrm{a}}$ & $7 \pm 1^{\mathrm{ab}}$ & $8 \pm 1^{\mathrm{b}}$ & $\mathrm{P}<0.05$ \\
\hline Total CD14+ & $7 \pm 1$ & $7 \pm 1$ & $8 \pm 1$ & NS \\
\hline Total CD20+ & $12 \pm 1^{\mathrm{a}}$ & $11 \pm 1^{\mathrm{a}}$ & $13 \pm 1^{\mathrm{b}}$ & $\mathrm{P}<0.01$ \\
\hline CD16+CD56+ & $8 \pm 1^{\mathrm{a}}$ & $13 \pm 1^{\mathrm{b}}$ & $7 \pm 1^{a}$ & $\mathrm{P}<0.0001$ \\
\hline Total CD16+ & $15 \pm 1^{\mathrm{a}}$ & $23 \pm 1^{\mathrm{b}}$ & $16 \pm 1^{\mathrm{a}}$ & $\mathrm{P}<0.0001$ \\
\hline Total CD45RO+ & $27 \pm 2^{\mathrm{a}}$ & $27 \pm 2^{\mathrm{a}}$ & $31 \pm 2^{\mathrm{b}}$ & $\mathrm{P}<0.001$ \\
\hline Total CD45RA+ & $64 \pm 2^{\mathrm{a}}$ & $64 \pm 2^{\mathrm{a}}$ & $58 \pm 2^{\mathrm{b}}$ & $\mathrm{P}<0.0001$ \\
\hline
\end{tabular}

"Values are means \pm SEM $(n=12)$. No significant differences were found between the baseline and post-treatment values, nor was there a significant diet effect. Therefore, the baseline and post-treatment data were pooled and diet groups combined in order to report the overall effect of exercise. Where a significant effect was found, differences between pre-exercise, post-exercise and recovery values were determined by lsmeans. Within a row, means that do not share a letter are different $(\mathrm{P}<0.05)$. NS, not significant.

pre-exercise $\square$ post-exercise $\square$ recovery

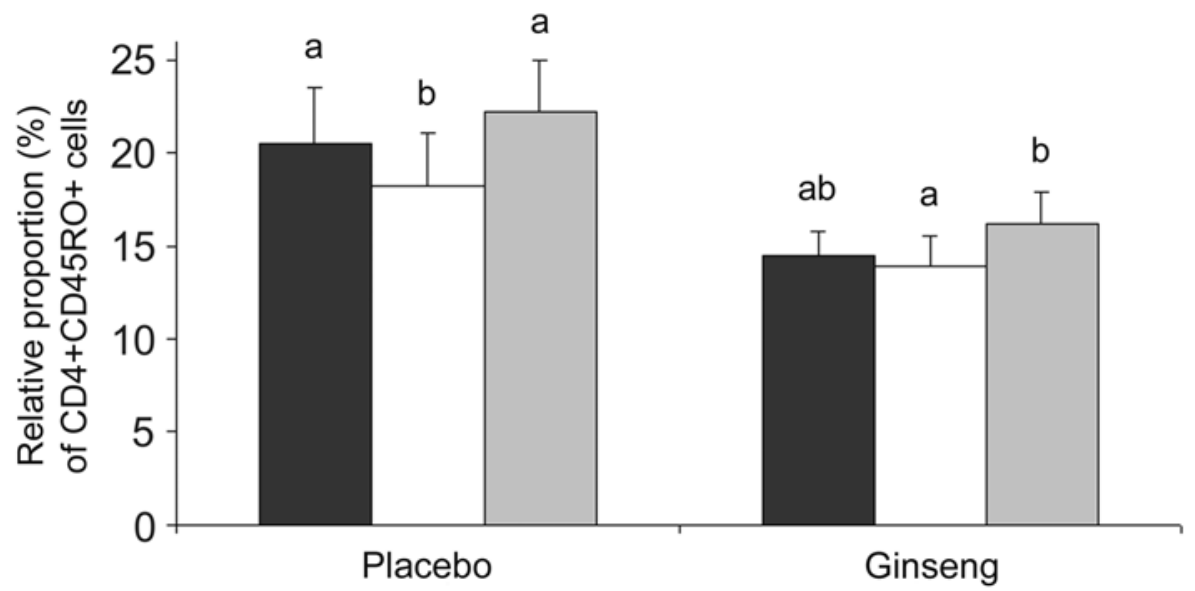

Fig. (1). Effect of exercise and diet treatment on the proportion of CD4+CD45RO+ cells in peripheral blood. Only the post-treatment data is shown. Bars represent the means \pm SEM ( $n=6$ per diet group). Where a significant effect of exercise was found, differences between preexercise, post-exercise and recovery values were determined by lsmeans. Within either the placebo or ginseng treatment groups, means that do not share a letter are different $(\mathrm{P}<0.05)$. Ginseng and placebo groups differed significantly $(\mathrm{P}=0.0002)$.

CD20+ cells were higher at recovery than immediate postexercise values $(\mathrm{P}<0.05)$. There was no effect of exercise on the proportions of $\mathrm{CD} 3+\mathrm{CD} 8+$ nor on $\mathrm{CD} 4+\mathrm{CD} 25+$, CD8+CD25+, or CD14+ cells.

\section{Neutrophil Oxidative Burst}

Neutrophil function measured at 5,10 and 15 min after PMA stimulation did not differ between the two groups at baseline. However, the unstimulated (time 0) neutrophil 


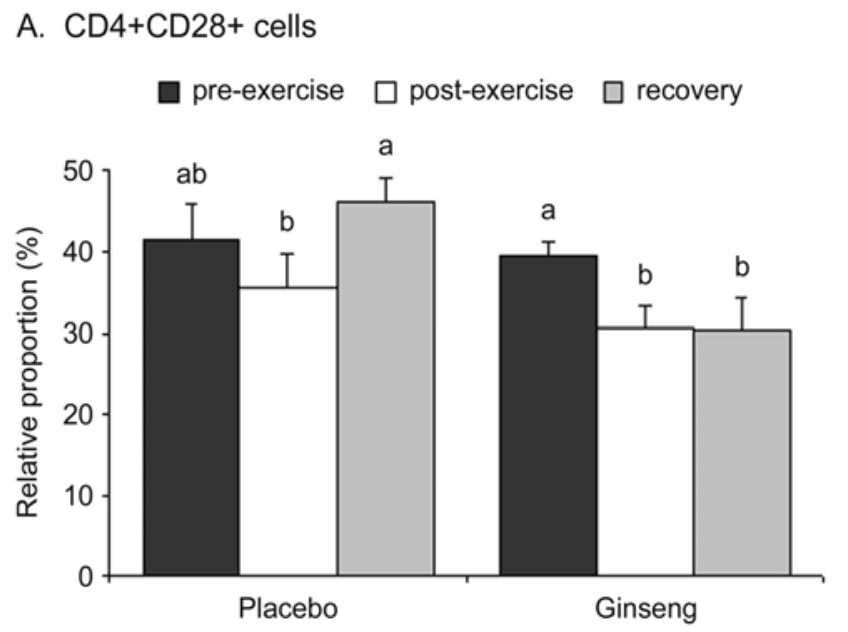

B. Total CD28+ cells
\[ \text { pre-exercise } \square \text { post-exercise } \square \text { recovery } \]

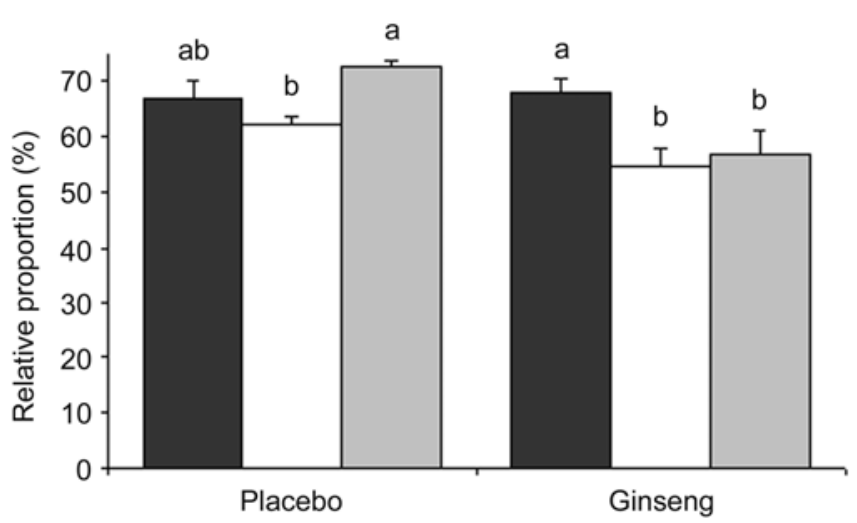

Fig. (2). Effect of exercise and diet treatment on the proportions of $\mathbf{A})$ CD4+CD28+ cells and $\mathbf{B}$ ) total CD28+ cells in peripheral blood. Only the post-treatment data is shown. Bars represent the means \pm SEM ( $n=6$ per diet group). Where a significant effect of exercise was found, differences between pre-exercise, post-exercise and recovery values were determined by lsmeans. Within either the placebo or ginseng treatment groups, means that do not share a letter are different $(\mathrm{P}<0.05)$. There was a significant interaction between diet and exercise for both CD4+CD28+ cells $(\mathrm{P}=0.01)$ and total $\mathrm{CD} 28+$ cells $(\mathrm{P}=0.03)$.

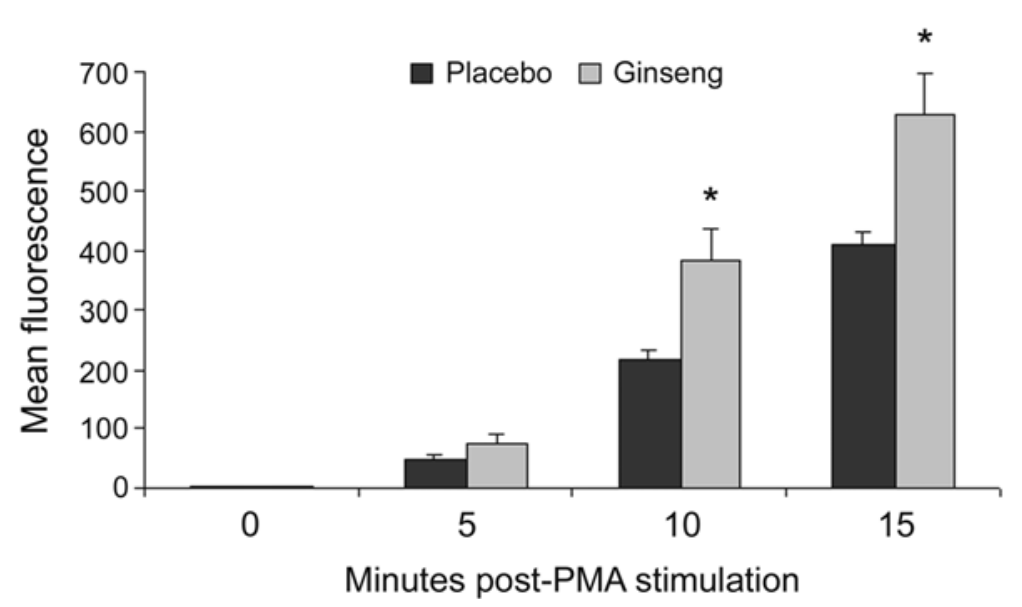

Fig. (3). Effect of diet treatment on peripheral blood neutrophil oxidative burst activity. Only the post-treatment data is shown. Bars represent the means \pm SEM ( $\mathrm{n}=6$ per diet group). * indicates a significant difference from the placebo group $(\mathrm{P}<0.05)$.

oxidative burst differed at baseline between women randomized to the experimental $(4.7 \pm 0.7, n=6)$ and control $(2.6 \pm$ $0.2, n=6)$ treatments. To control for this in testing for the effects of diet and exercise, the baseline value was used as a covariate. There was no effect of exercise on neutrophil oxidative burst so the exercise timepoints were combined to report the overall effect of diet (Fig. 3). Neutrophil oxidative burst activity measured prior to and 5 minutes after PMA stimulation did not differ between diet groups, however the neutrophil oxidative burst was significantly higher for ginseng-treated subjects compared to control subjects after 10 and 15 min stimulation with PMA ( $\mathrm{P}<0.05$; Fig. 3).

\section{Peripheral Mononuclear Cell [ $\left.{ }^{3} \mathbf{H}\right]-$ Thymidine Incorpora- tion}

The experimental and control groups differed at baseline in the PWM stimulation index. Thus, baseline values were used as covariates to test for diet and exercise effects. There were no effects of diet on lymphocyte proliferation, nor were there differences between the baseline and post-treatment data, and so the baseline and post-treatment data were pooled, and the diet groups combined, to report the overall effects of exercise (Table 3). Exercise did not affect the proliferation of unstimulated lymphocytes. After stimulation with PHA, lymphocyte proliferation (measured by the absolute rate of $\left[{ }^{3} \mathrm{H}\right]$-thymidine uptake as well as by stimulation index) was significantly higher at recovery $(\mathrm{t}=66 \mathrm{~min})$ compared to immediately post-exercise $(\mathrm{t}=36 \mathrm{~min})$ $(\mathrm{P}<0.05)$. The exercise protocol had no effect on PWMstimulated lymphocyte proliferation (Table $\mathbf{3}$ ).

\section{Natural Killer Cell Cytotoxicity}

There were no differences between groups at baseline in either of the NK cell cytotoxicity measures (i.e. \% specific lysis at each effector to target cell ratio, total lytic units). There were no effects of diet on the \% specific lysis at each ratio, nor were there differences between the baseline and post-treatment data, and so the baseline and post-treatment 
Table 3. Effect of Exercise on Lymphocyte Proliferation*

\begin{tabular}{|c|c|c|c|c|}
\hline Mitogen & Pre-Exercise $(t=-15$ min $)$ & Post-Exercise $(t=36$ min $)$ & Recovery $(t=66 \mathrm{~min})$ & Exercise P-Value \\
\hline PHA (SI) & $137 \pm 16^{\mathrm{ab}}$ & $121 \pm 11^{\mathrm{b}}$ & $159 \pm 16^{\mathrm{a}}$ & $\mathrm{P}<0.05$ \\
\hline PWM (dpm) & $54891 \pm 3896$ & $47198 \pm 3273$ & $56280 \pm 5188$ & NS \\
\hline
\end{tabular}

"Values are means \pm SEM $(n=12)$. No significant differences were found between the baseline and post-treatment values, nor was there a significant diet effect. Therefore, the baseline and post-treatment data were pooled and diet groups combined in order to report the overall effect of exercise. Where a significant effect was found, differences between preexercise, post-exercise and recovery values were determined by lsmeans. Within a row, means that do not share a letter are different $(\mathrm{P}<0.05)$. Dpm, disintegrations per minute; NS, not significant; PHA, phytohemagglutinin; PWM, pokeweed mitogen; SI, stimulation index $\left[{ }^{3} \mathrm{H}\right.$-thymidine (dpm) incorporated by stimulated cells / ${ }^{3} \mathrm{H}$-thymidine incorporated by unstimulated cells]; UNS, unstimulated.

data were pooled, and the diet groups combined, to report the overall effects of exercise (Table 4). At all effector-to-target cell ratios tested, NK cell cytotoxicity values were higher (only the lowest and highest ratio did not reach statistical significance) immediately post-exercise $(\mathrm{t}=36 \mathrm{~min})$ and then decreased $(\mathrm{P}<0.05)$ to pre-exercise levels at recovery (Table 4). There were no effects of diet or exercise on total lytic units $\left(13.4 \pm 2.1 \times 10^{3}\right.$ at baseline vs. $11.2 \pm 1.1 \times 10^{3}$ post-treatment, $\mathrm{n}=11)$.

\section{DISCUSSION}

Few studies have been conducted to examine the effect of ginseng consumption on exercise-induced immune changes among human subjects. The present study is, to our knowledge, the first to measure the effects of regular daily ginseng consumption on the immune response to exercise in women. Here, we report that consumption of a ginsenosidecontaining extract of North American ginseng for four weeks altered the proportions of both $\mathrm{CD} 4+\mathrm{CD} 28+$ and total CD28+ cells as well as CD4+CD45RO+ cells in peripheral blood, and increased neutrophil oxidative burst activity (Fig. 4). These results differ somewhat from those of a study we conducted in sedentary young men [23], in which ginseng consumption reduced peripheral blood concentrations of CD8+ $\mathrm{T}$ cells but had no effect on CD28+ or CD45RO+ cells, or neutrophil function. These differences suggest that the effects of ginseng on the immune response to exercise may differ between men and women, an issue that deserves further study.
In a randomized controlled trial of healthy men and women, Engels et al. did not find an effect of consuming ginseng $(400 \mathrm{mg} / \mathrm{d}$ of $\mathrm{G} 115$, containing $4 \% \mathrm{w} / \mathrm{w}$ ginsenosides, for 8 weeks) on secretory IgA levels in saliva before or after intense exercise [21]. Although IgA was not measured in the present study, ginseng did not affect the exerciseinduced change in $\mathrm{B}$ cells nor the response to a polyclonal mitogen that stimulates B cells (PWM). Our work and that of Engels et al. suggests that the immune effects of ginsenosides during exercise stress may not be via changes in humoral immunity.

Gaffney et al. conducted a double-blind, randomized, placebo-controlled trial to investigate the effects of ginseng consumption on peripheral blood lymphocyte concentrations among male endurance athletes [22]. In this study, blood samples were obtained from subjects at rest before and after 6 weeks of consuming the equivalent of $2 \mathrm{~g} /$ day of dried Panax ginseng root, or placebo. The authors reported no significant effects of ginseng consumption on lymphocyte concentrations in blood ( $\mathrm{T}$ cells, $\mathrm{B}$ cells, NK cells) at rest [22]. However, the results of the current study suggest that consumption of a ginsenoside-containing North American ginseng extract for four weeks can significantly alter the distribution of specific $\mathrm{T}$ cell populations, without changing the relative proportion of CD4+ cells. Ginseng-treated subjects exhibited lower proportions of antigen mature CD4+CD45RO+ peripheral blood cells before (albeit, not significantly lower, which may be due to the small sample size) and after exercise, and also experienced a sustained

Table 4. Effect of Exercise on Natural Killer Cell Cytotoxic Activity*

\begin{tabular}{|c|c|c|c|c|}
\hline Effector-to-target Ratio & Pre-Exercise $(t=-15 \mathrm{~min})$ & Post-Exercise $(t=36$ min $)$ & Recovery $(t=66 \mathrm{~min})$ & Exercise P-Value \\
\hline $6.25: 1$ & $18.2 \pm 1.8^{\mathrm{a}}$ & $29.8 \pm 3.4^{\mathrm{b}}$ & $17.0 \pm 1.6^{\mathrm{a}}$ & $\mathrm{P}<0.05$ \\
\hline $12.5: 1$ & $33.3 \pm 2.8^{\mathrm{a}}$ & $42.3 \pm 2.4^{\mathrm{b}}$ & $30.0 \pm 2.0^{\mathrm{a}}$ & $\mathrm{P}<0.01$ \\
\hline $50: 1$ & $55.3 \pm 3.4^{\mathrm{ab}}$ & $58.3 \pm 1.9^{\mathrm{b}}$ & $49.3 \pm 2.6^{\mathrm{a}}$ & $\mathrm{P}<0.05$ \\
\hline
\end{tabular}

${ }^{*}$ Values are means \pm SEM $(n=12)$. No significant differences were found between the baseline and post-treatment values, nor was there a significant diet effect. Therefore, the baseline and post-treatment data were pooled and diet groups combined in order to report the overall effect of exercise. Where a significant effect was found, differences between preexercise, post-exercise and recovery values were determined by lsmeans. Within a row, means that do not share a letter are different $(\mathrm{P}<0.05)$. 
Effect of Exercise Effect of Ginseng

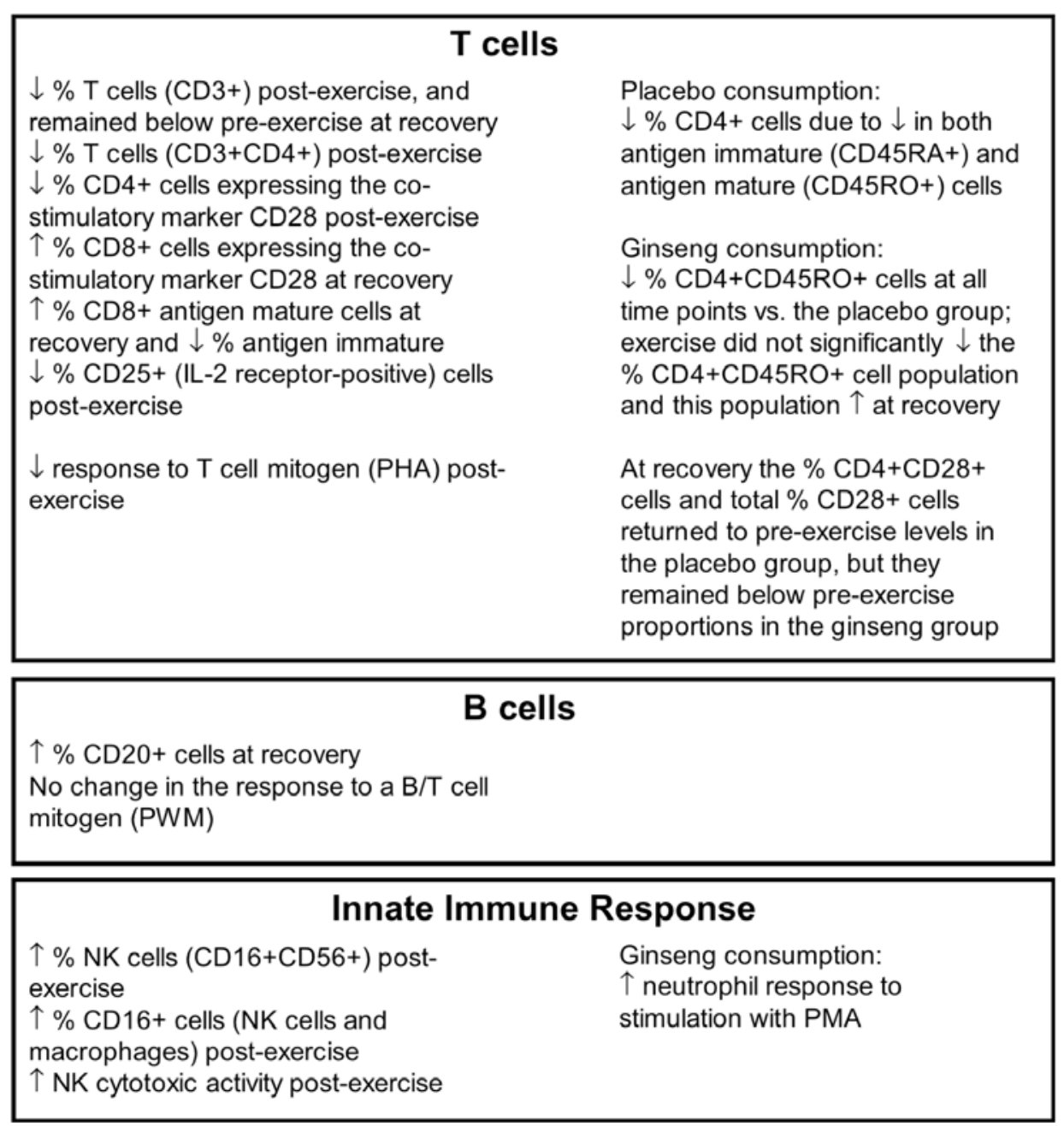

Fig. (4). Summary of the effects of a single bout of moderate intensity exercise on immune function in women consuming ginseng or a placebo. The measured changes in $\mathrm{T}$ cells, B cells and innate immune cell types and function are summarized (unless otherwise stated) as the change from pre-exercise levels.

reduction in the proportions of total CD28+ and CD4+CD28+ cells during recovery from exercise. CD28 is an important molecule involved in the activation of CD4+ cells [39] and the implications of this on immune function in the subjects consuming ginseng are not known, but the ability of their cells to respond to PHA (a polyclonal T cell mitogen) was not affected.

Neutrophils are the first line of defense against infectious challenges and play an important role in initiating tissue repair. The ability to produce free radicals (oxidative burst) is an important activity of neutrophils [40]. Despite what has been demonstrated by others after exercise [13, 41, 42], we did not observe a stimulatory effect of exercise on neutrophil oxidative burst activity in either of our groups. It is possible that the exercise protocol used in the current study was of an intensity (mean intensity was just less than $70 \% \mathrm{VO}_{2 \max }$ ) that was not sufficient to influence neutrophil function in sedentary women. However, consumption of ginseng resulted in a significantly higher mitogen-stimulated neutrophil oxidative burst activity pre, post and during recovery from exercise.
Our data suggests that regular consumption of ginseng may be beneficial to this defense of the innate immune system.

The effects of exercise on immune function observed in the current study are for the most part consistent with the literature. The increase in NK cytotoxic activity postexercise observed in the present study and reported by others after moderate to high intensity exercise $[13,41]$ was primarily due to the increase in NK cell numbers (CD16+CD56+), as the lytic units (the activity per cell) did not change significantly with exercise. While the absolute concentrations of leukocytes and lymphocytes are reportedly increased in peripheral blood immediately post-exercise, the relative proportion of $\mathrm{T}$ cells, in particular CD4+ T cells, is reportedly decreased, due to the fact that NK cell numbers increase proportionately more than other mononuclear cell populations $[13,41]$. Our work extends the current literature by looking at specific $\mathrm{T}$ cell populations during exercise, and we have shown that the CD4+ cells that decrease with exercise are those that express CD28 and are antigen naïve (CD45RA+). We observed an increased proportion of antigen mature $(\mathrm{CD} 45 \mathrm{RO}+)$ cells and lower proportion of antigen naïve 
$(\mathrm{CD} 45 \mathrm{RA}+)$ cells during the recovery period, which is consistent with reports that primarily memory but not naïve lymphocytes are recruited to the blood during exercise [41]. Our findings, at recovery, suggest that within the CD8+ population there are proportionately more cells expressing $\mathrm{CD} 28$ and are antigen mature (CD45RO+). This is suggestive of the recruitment of an important population of regulatory cells [43] that could be central to conferring some of the immune benefits of exercise on immunity.

The observed reduction in lymphocyte proliferation after stimulation with a polyclonal $\mathrm{T}$ cell mitogen (PHA) immediately post-exercise is supported by reports that T-lymphocyte proliferative responses are reduced post-exercise [13, 41]. This effect has been largely attributed to the decline in the relative proportion of $\mathrm{T}$ cell found in blood post-exercise [41]. Our results support this finding but suggest it is the reduction in T-helper cells $(\mathrm{CD} 3+\mathrm{CD} 4+)$, specifically those expressing the co-stimulatory marker CD28 that might be contributing to the lower proliferation rate. The costimulatory marker CD28 is a molecule that is needed for cells to be activated [39].

\section{CONCLUSION}

Much anecdotal evidence supports the use of herbs to enhance physical performance and immune function, but controlled clinical trials have only recently been conducted to verify these claims. Consumption of a standardized North American ginseng extract for four weeks improved the ability of neutrophils to respond to stimulation and produced changes that are consistent with less $\mathrm{T}$ cell activation after an acute exercise stress in women.

\section{ABBREVIATIONS}

$\begin{array}{ll}\mathrm{BMI} & =\text { body mass index } \\ \mathrm{dpm} & =\text { disintegrations per minute } \\ \mathrm{kp} & =\text { kiloponds } \\ \mathrm{NK} & =\text { natural killer } \\ \text { PHA } & =\text { phytohemagglutinin } \\ \text { PMA } & =\text { phorbol myristate acetate } \\ \text { PWM } & =\text { pokeweed mitogen } \\ \text { REE } & =\text { resting energy expenditure } \\ \mathrm{SEM} & =\text { standard error of the mean } \\ \mathrm{VO}_{2 \mathrm{max}} & =\text { maximal oxygen consumption } \\ \mathrm{VT} & =\text { ventilatory threshold }\end{array}$

\section{ACKNOWLEDGEMENTS}

The authors would like to acknowledge Susan Goruk for her outstanding technical assistance, Stephanie Alloway and Sherri Foster for coordinating the clinical aspects of the study, Alex Game for conducting the fitness testing, and Linda Johnson for conducting the blood draws. Statistical consultation was provided by Dr. Laki Goonewardene in the Department of Agricultural, Food and Nutritional Science at the University of Alberta. Funding for this study was provided by Chai-Na-Ta Corp., Richmond, BC, Canada and an Industry Matching Grant from the Natural Sciences and Engineering Research Council of Canada.

\section{REFERENCES}

[1] Kitts D, Hu C. Efficacy and safety of ginseng. Publ Health Nutr 2000; 3: 473-85.

[2] Bucci LR. Selected herbals and human exercise performance. Am J Clin Nutr 2000; 72: 624S-36S.

[3] Bahrke MS, Morgan WR. Evaluation of the ergogenic properties of ginseng: an update. Sports Med 2000; 29: 113-33.

[4] Tan BK, Vanitha J. Immunomodulatory and antimicrobial effects of some traditional chinese medicinal herbs: a review. Curr Med Chem 2004; 11: 1423-30.

[5] Liu J, Wang S, Liu H, Yang L, Nan G. Stimulatory effect of saponin from Panax ginseng on immune function of lymphocytes in the elderly. Mech Ageing Dev 1995; 83: 43-53.

[6] Lee EJ, Ko E, Lee J, et al. Ginsenoside Rg1 enhances CD4(+) Tcell activities and modulates Th1/Th2 differentiation. Int Immunopharmacol 2004; 4: 235-44.

[7] Scaglione F, Ferrara F, Dugnani S, et al. Immunomodulatory effects of two extracts of Panax ginseng C.A. Meyer. Drugs Exp Clin Res 1990; 16: 537-42.

[8] Scaglione F, Cattaneo G, Alessandria M, Cogo R. Efficacy and safety of the standardised Ginseng extract G115 for potentiating vaccination against the influenza syndrome and protection against the common cold [corrected]. Drugs Exp Clin Res 1996; 22: 65-72.

[9] McElhaney JE, Gravenstein S, Cole SK, et al. A placebo-controlled trial of a proprietary extract of North American ginseng (CVTE002) to prevent acute respiratory illness in institutionalized older adults. J Am Geriatr Soc 2004; 52: 13-9.

[10] Predy GN, Goel V, Lovlin R, et al. Efficacy of an extract of North American ginseng containing poly-furanosyl-pyranosyl-saccharides for preventing upper respiratory tract infections: a randomized controlled trial. CMAJ 2005; 173: 1043-8.

[11] Block KI, Mead MN. Immune system effects of echinacea, ginseng, and astragalus: a review. Integr Cancer Ther 2003; 2: 247-67.

[12] Nieman DC. Current perspective on exercise immunology. Curr Sports Med Rep 2003; 2: 239-42.

[13] Rowbottom DG, Green KJ. Acute exercise effects on the immune system. Med Sci Sports Exerc 2000; 32: S396-S405.

[14] Ceddia MA, Price EA, Kohlmeier CK, et al. Differential leukocytosis and lymphocyte mitogenic response to acute maximal exercise in the young and old. Med Sci Sports Exerc 1999; 31: 829-36.

[15] Shore S, Shinkai S, Rhind S, Shephard RJ. Immune responses to training: how critical is training volume? J Sports Med Phys Fitness 1999; 39: 1-11.

[16] Rhind SG, Shek PN, Shinkai S, Shephard RJ. Effects of moderate endurance exercise and training on in vitro lymphocyte proliferation, interleukin-2 (IL-2) production, and IL-2 receptor expression. Eur J Appl Physiol Occup Physiol 1996; 74: 348-60.

[17] Gabriel H, Kullmer T, Schwarz L, et al. Circulating leucocyte subpopulations in sedentary subjects following graded maximal exercise with hypoxia. Eur J Appl Physiol Occup Physiol 1993; 67: 348-53.

[18] Rodriguez AB, Barriga C, de la Fuente M. Phagocytic function of blood neutrophils in sedentary young people after physical exercise. Int J Sports Med 1991; 12: 276-80.

[19] Hwang HJ, Kwak YS, Yoon GA, et al. Combined effects of swim training and ginseng supplementation on exercise performance time, ROS, lymphocyte proliferation, and DNA damage following exhaustive exercise stress. Int J Vitam Nutr Res 2007; 77: 289-96.

[20] Pannacci M, Lucini V, Colleoni F, et al. Panax ginseng C.A. Mayer G115 modulates pro-inflammatory cytokine production in mice throughout the increase of macrophage toll-like receptor 4 expression during physical stress. Brain Behav Immun 2006; 20 : 546-51.

[21] Engels HJ, Fahlman MM, Wirth JC. Effects of ginseng on secretory $\operatorname{IgA}$, performance, and recovery from interval exercise. Med Sci Sports Exerc 2003; 35: 690-6.

[22] Gaffney BT, Hugel HM, Rich PA. The effects of Eleutherococcus senticosus and Panax ginseng on steroidal hormone indices of stress and lymphocyte subset numbers in endurance athletes. Life Sci 2001; 70: 431-42.

[23] Biondo PD, Robbins SJ, Walsh JD, McCargar LJ, Harber VJ, Field CJ. A randomized controlled crossover trial of ginseng consumption on the immune response to moderate exercise in healthy sedentary men. Appl Physiol Nutr Metab 33(5): 966-75.

[24] Bhambhani Y, Singh M. Ventilatory thresholds during a graded exercise test. Respiration 1985; 47: 120-8. 
[25] Thoden JS. Testing aerobic power. $2^{\text {nd }}$ ed. In: MacDougall JD, Wenger HA, Green HJ, Eds. Physiological testing of the highperformance athlete. Champaign, IL: Human Kinetics, 1991; pp. 108-73.

[26] Kitts DD, Wijewickreme AN, Hu C. Antioxidant properties of a North American ginseng extract. Mol Cell Biochem 2000; 203: 110 .

[27] Siegel RK. Ginseng abuse syndrome. Problems with the panacea. JAMA 1979; 241: 1614-5.

[28] Baecke JA, Burema J, Frijters JE. A short questionnaire for the measurement of habitual physical activity in epidemiological studies. Am J Clin Nutr 1982; 36: 936-42.

[29] Pols MA, Peeters PH, Bueno-De-Mesquita HB, et al. Validity and repeatability of a modified Baecke questionnaire on physical activity. Int J Epidemiol 1995; 24: 381-8.

[30] Brodie D, Moscrip V, Hutcheon R. Body composition measurement: a review of hydrodensitometry, anthropometry, and impedance methods. Nutrition 1998; 14: 296-310.

[31] Motley HL. Comparison of a simple helium closed with the oxygen open-circuit method for measuring residual air. Am Rev Tuberc 1957; 76: 601-15.

[32] Siri WE. The gross composition of the body. Adv Biol Med Phys 1956; 4: 239-80.

[33] Weir JB. New methods for calculating metabolic rate with special reference to protein metabolism. J Physiol 1949; 109: 1-9.

[34] Thuma JR, Gilders R, Verdun M, Loucks AB. Circadian rhythm of cortisol confounds cortisol responses to exercise: implications for future research. J Appl Physiol 1995; 78: 1657-64.
[35] Pratt VC, Tredget EE, Clandinin MT, Field CJ. Alterations in lymphocyte function and relation to phospholipid composition after burn injury in humans. Crit Care Med 2002; 30: 1753-61.

[36] Field CJ, Thomson CA, Van Aerde JE, et al. Lower proportion of CD45R0+ cells and deficient interleukin- 10 production by formulafed infants, compared with human-fed, is corrected with supplementation of long-chain polyunsaturated fatty acids. J Pediatr Gastroenterol Nutr 2000; 31: 291-9.

[37] Fairey AS, Courneya KS, Field CJ, et al. Randomized controlled trial of exercise and blood immune function in postmenopausal breast cancer survivors. J Appl Physiol 2005; 98: 1534-40.

[38] Wang Z, Goonewardene LA. The use of MIXED models in the analysis of animal experiments with repeated measures data. Can J Anim Sci 2004; 84: 1-11.

[39] Wang S, Chen L. T lymphocyte co-signaling pathways of the B7CD28 family. Cell Mol Immunol 2004; 1: 37-42.

[40] Malech HL. The role of neutrophils in the immune system: an overview. Methods Mol Biol 2007; 412: 3-11.

[41] Pedersen BK, Hoffman-Goetz L. Exercise and the immune system: regulation, integration, and adaptation. Physiol Rev 2000; 80: 1055-81.

[42] Nehlsen-Cannarella SL. Cellular responses to moderate and heavy exercise. Can J Physiol Pharmacol 1998; 76: 485-9.

[43] Sansom DM, Walker LSK. The role of CD28 and cytotoxic Tlymphocyte antigen-4 (CTLA-4) in regulatory T-cell biology. Immunol Rev 2006; 212: 131-48.

Received: July 27, 2008

(C) Biondo et al.; Licensee Bentham Open.

This is an open access article licensed under the terms of the Creative Commons Attribution Non-Commercial License (http://creativecommons.org/licenses/by-nc/3.0/) which permits unrestricted, non-commercial use, distribution and reproduction in any medium, provided the work is properly cited. 